\title{
Notes on the vocalizations of Azure-crested Flycatcher (Myiagra azureocapilla)
}

Peter Boesman

In the following we briefly analyze and compare voice of the three races of Azure-crested Flycatcher (Myiagra azureocapilla). We also try to quantify the extent of any vocal differences using the criteria proposed by Tobias et al. (2010), as a support for taxonomic review. We have made use of sound recordings available on-line from Xeno Canto (XC) and Macaulay Library (ML).

\section{Race azureocapilla $(\mathrm{n}=9)$}

Most common vocalization is a series of identical whistles given at a fast pace.

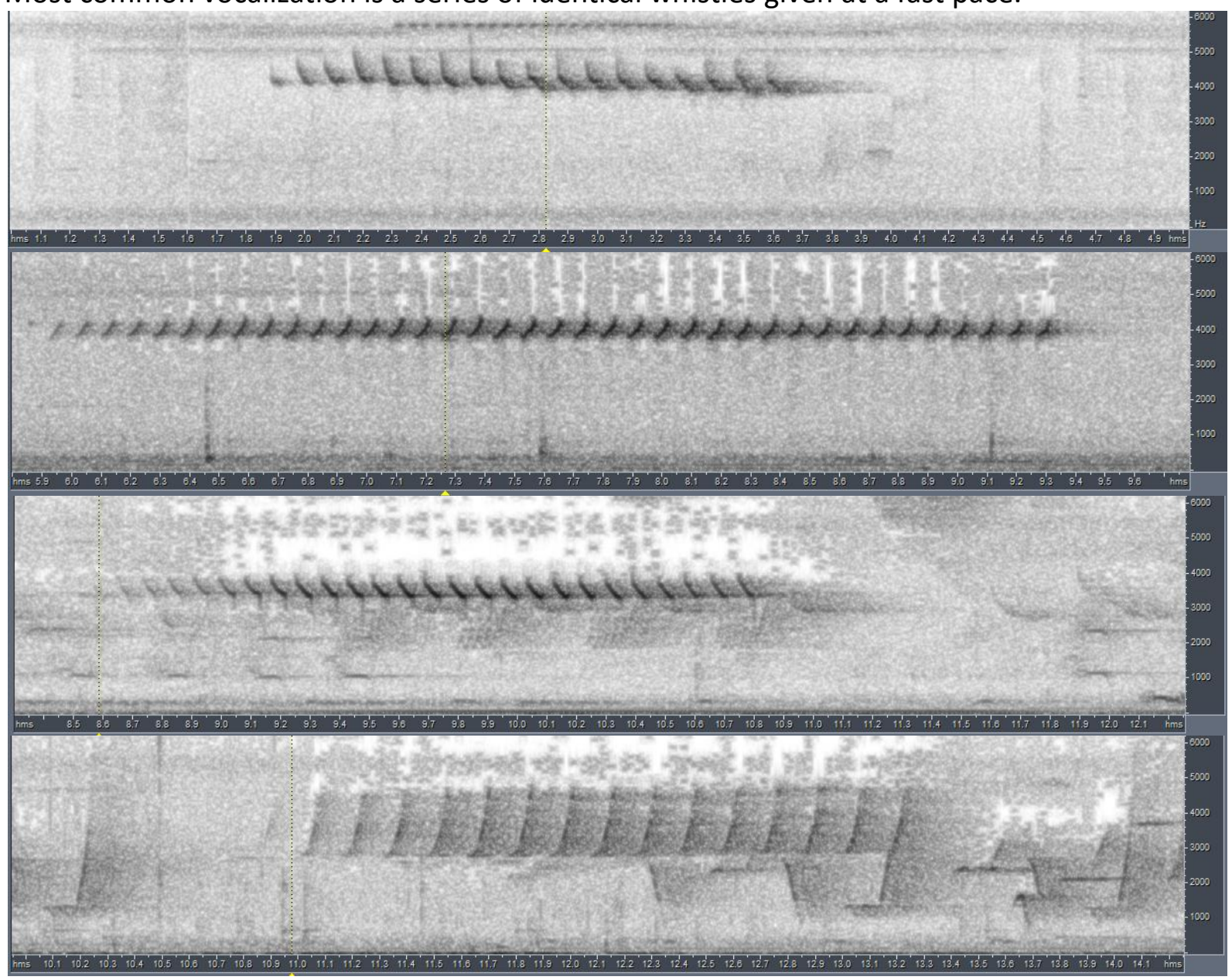

other vocalizations e.g.:

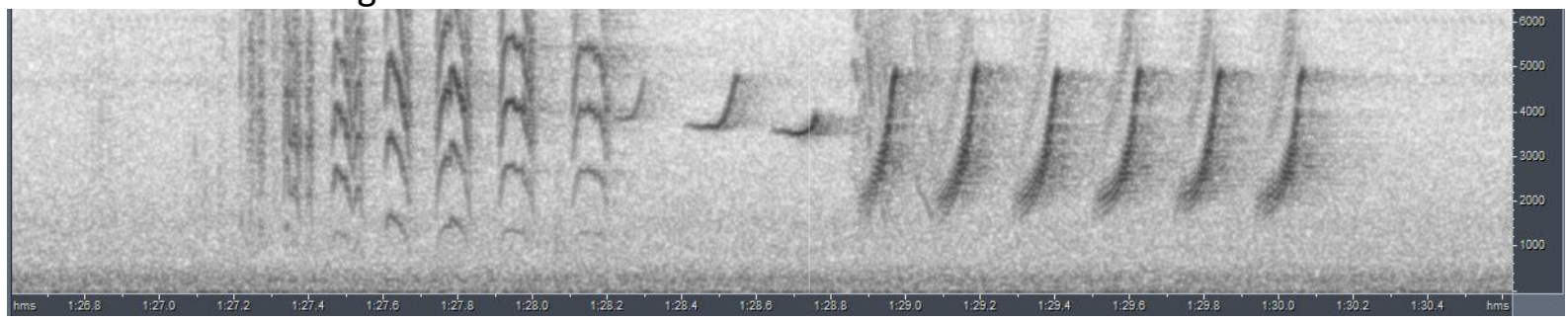




\section{HANDBOOK OF THE BIRDSPITUE WORLD}

\section{ORNITHOLOGICAL NOTES}

\section{Race whitneyi $(\mathrm{n}=5)$}

Song similar to azureocapilla:

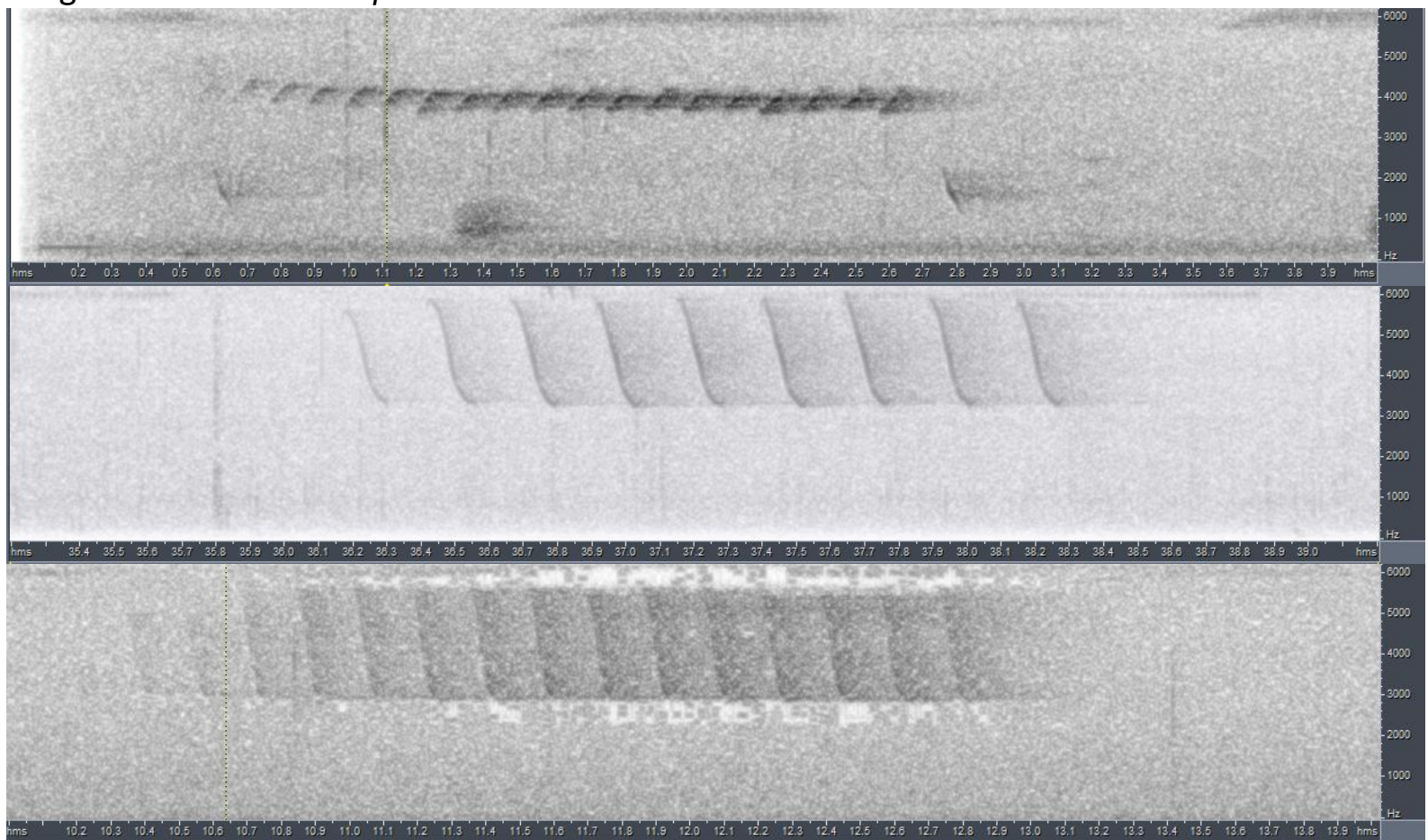

and also a slower-paced series:

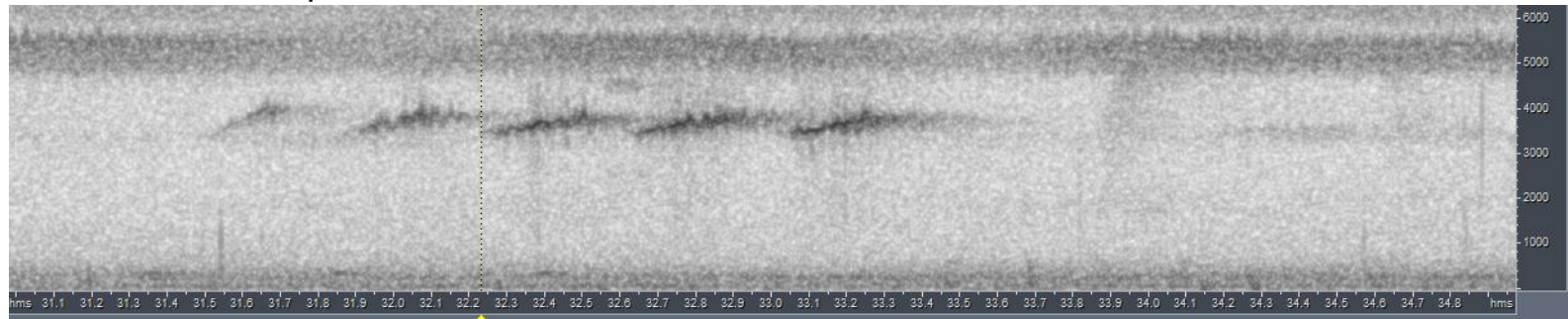

Race castaneigularis $(\mathrm{n}=1)$

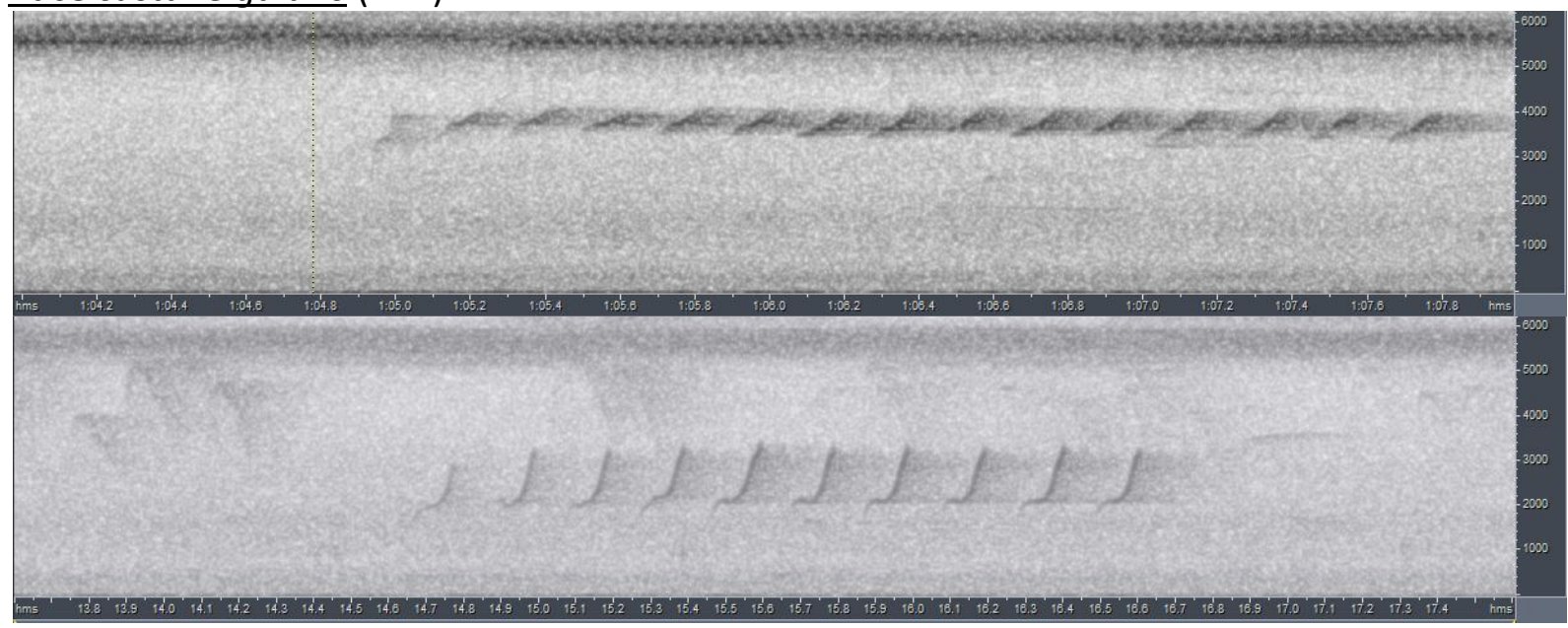



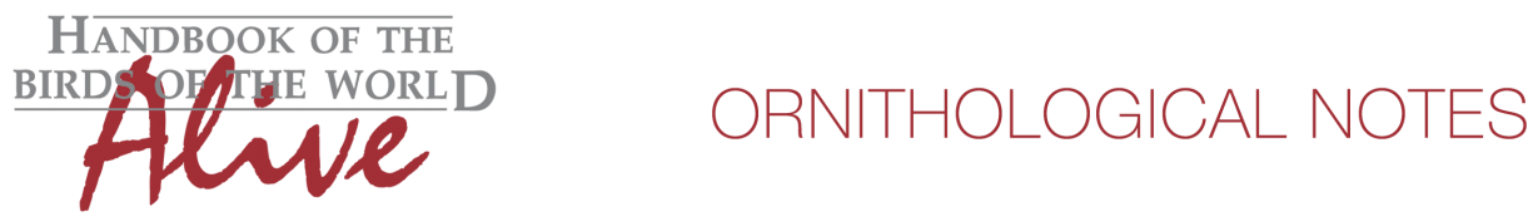

The fast almost trilled series with notes in a narrow frequency range and the slower-paced series with notes over a larger frequency range are likely functionally two different vocalizations.

With so few examples of whitneyi and castaneigularis, consistent differences compared to azureocapilla are difficult to prove. Also, the frequency of delivery of the different vocalizations is impossible to quantify, but azureocapilla seems to utter the fast almost trilled series much more than other races.

whitneyi may have a somewhat higher-pitched slow series compared to azureocapilla. castaneigularis seems to differ from both other races in somewhat slower trilled series and much lower frequency of slow series.

These differences are obviously quite speculative, and need to be confirmed by more recordings. If differences prove to be consistent, this may lead to estimated scores of 2-3.

This note was finalized on 19th January 2015 , using sound recordings available on-line at that moment. We would like to thank in particular the sound recordists who placed their recordings for this species on XC and ML: Michael Anderson, Matthias Feuersenger, Mark O'Brien and Douglas Pratt.

\section{References}

Tobias, J.A., Seddon, N., Spottiswoode, C.N., Pilgrim, J.D., Fishpool, L.D.C. \& Collar, N.J. (2010). Quantitative criteria for species delimitation. Ibis 152(4): 724-746.

\section{Recommended citation}

Boesman, P. (2016). Notes on the vocalizations of Azure-crested Flycatcher (Myiagra azureocapilla). HBW Alive Ornithological Note 196. In: Handbook of the Birds of the World Alive. Lynx Edicions, Barcelona. (retrieved from http://www.hbw.com/node/932141 on 30 August 2016). 